\title{
Health Risk Behaviour as Depicted in the Media
}

\author{
K. Lalitha ${ }^{1 *}$, B. Venkata Subbaiah ${ }^{2}$
}

\section{ABSTRACT}

Media plays a very significant and influential role in our day today life. Everyday programs include advertisement and entertainment programmes like serials etc., but now a days, everyday at least five risky behaviours are witnessed by the public. The present study was planned to know the role of media in relation to health risk behavior. The selection of the sample was done randomly in Siddavatam village and Kadapa town. After obtaining prior information, the subjects were contacted individually at their home and explained the purpose of the study and seeking their co-operation. The obtained data was analyzed and results show that health risk behavior is commonly witnessed in the media and found less preventive measures to reduce health risk behaviour. The links between media consumption and smoking and alcohol use also are strong and there is good evidence that they are causal. Currently there is need of high-quality research to make it possible to say whether the links are causal. To better understand the effect of the media on youth risk behavior, researchers will have to develop comprehensive explanatory models that include socioeconomic and cultural variables.

Keywords: Health Risk Behavior, Depiction in Media, Attitude

Media technology is an integral part of lives of everybody in the twenty-first century. The world of electronic media, however, is changing dramatically. Now television is equally competing with new electronic devises like mobiles, i Pods etc., But in a country like India, Television plays major role in entertainment where as it is a fact that electronic media has strong influence on people particularly teens. Recent incidents reported in media clearly indicate that violence is increased due to repeated exposure to violent scenes. The public is not always informed of possible health risks or preventative measures; not all health messages are easily understood, and some messages contain misleading or false information (Signorielli, 1993). Many would agree that the media are the biggest educators in today’s society (Yates, 1999).

\footnotetext{
${ }^{1}$ Asst. Professor, Department of Psychology, Y.V. University, Kadapa

${ }^{2}$ P.G. Student, Department of Psychology, Y.V. University, Kadapa

*Responding Author

(C) 2016 I K Lalitha, V Subbaiah; licensee IJIP. This is an Open Access Research distributed under the terms of the Creative Commons Attribution License (http://creativecommons.org/licenses/by/2.0), which permits unrestricted use, distribution, and reproduction in any Medium, provided the original work is properly cited.
} 


\section{Health Risk Behaviour as Depicted in the Media}

Among all the age groups children and youth are most affected. Youth is much affected with regular watching and television and health risk behaviour is also high in this stage. It is a fact that health behaviors do not occur in isolation. They grow out of complex interactions at the individual, peer, family, school, community, and societal levels. The adolescent health risk behaviors include obesity (which is in large part due to inactivity and consumption of highcalorie foods), smoking, alcohol use, early sexual initiation, and violence.

Another effective form of parental involvement is active mediation. When parents watch TV with their children and talk about the content viewed, children demonstrate improved comprehension of content and TV production techniques (Corder-Bolz, 1980). The high volume of alcohol and tobacco advertisements makes media literacy training a must for young people. Students can develop a design for a pester or series of pesters to warn about the dangers of alcohol or make others aware of how advertisers target adolescents. The posters can be used in the school, library or community. Such an exercise helps students understand the process of creating media messages and makes them more aware of how advertisers target young audiences (Considine \& Haley, 1992).

113 Research on parental monitoring of media use has had mixed findings. The share of parents who actively supervise their children's media use varies from study to study (Dorr \& Rabin, 1995). Various technologies have been developed to help parents monitor their children's electronic media use. Parents can, for instance, control children's exposure to media content by selecting videotapes for their children. However, research suggests that children typically watch videos that are similar to what they watch on broadcast television (Wachter \& Kelly, 1998). However, research over the past forty years suggests that less than half of parents enforced TV viewing limits or regularly discussed TV content with their children, whatever their ages (Abelman, 2001). Kim (2001) study results reveal that Korean adolescents showed high prevalence of smoking, drinking alcohol, bad eating habits, and viewing pornography; and very low prevalence, however, of sexual intercourse and illegal drug use. In addition to this, the findings revealed that the sub domains in adolescents' negative health behavior were statistically correlated with the sub dimensions of a psychological factor. Smoking on television remains widespread in prime-time programming. Little data exist about links between smoking as portrayed on television and in music videos and when adolescents begin to smoke. Gidwani study found important associations between how much adolescents attached TV and when they began smoking. Adolescents who watched more than five hours of TV a day were almost six times more likely to start smoking than those who watched two hours or less a day. Those who watched more than four to five hours of TV a day were more than five times more likely to start smoking than those who watched two hours or less (Gidwani et al., 2002).

More than half (53 percent) of eight- to eighteen-year-olds have reported that their parents set no rules about watching T.V. Among those who reported having rules, only 20 percent indicated that those rules are enforced "most of the time" (Roberts et al., 2005). Message framing is an 


\section{Health Risk Behaviour as Depicted in the Media}

effective message tailoring strategy that has been well-studied in the psychology literature over the past 20-plus years across a breadth of health behaviors while being severely understudied in the nursing literature. Numerous variables, especially those related to individual differences, have been shown to moderate message framing effects, a finding of great utility for nursing (Rachel, 2010). Risky health behaviors such as smoking, drinking alcohol, drug use, unprotected sex, and poor diets and sedentary lifestyles (leading to obesity) are major source of preventable deaths. The Integrative Model of Adolescent Health Risk Behavior was developed to guide adolescent nursing research using existing theoretical and empirical data. Components include protective/escalatory factors, risk stimulus, maturity of judgment (as a meditational influence), and the risk decision (dichotomized into risk avoidance and taking). The models facilitate development of nursing interventions to increase health protection by discouraging adolescents from making unhealthy choices (Heidi, 2010). Health risk behaviour leads the consequences of risky health behaviors for economic outcomes such as medical care costs, educational attainment, employment, wages, and crime (John, 2011). John et al., (2011) studied risky health behaviors such as smoking, drinking alcohol, drug use, unprotected sex, and poor diets and sedentary lifestyles (leading to obesity) are a major source of preventable deaths. traditional economic approaches emphasizing utility maximization that, under certain assumptions, result in Pareto-optimal outcomes and a limited role for policy interventions. It also details non-traditional models (e.g. involving hyperbolic time discounting or bounded rationality) that even without market imperfections can result in suboptimal outcomes for which government intervention has greater potential to increase social welfare.

Health risk behaviour includes smoking, drinking, sexual initiation, violence and aggressive behaviour. But repeated exposure these kind of scenes in the media also stimulates this behavior (Kelly et al., 2006). The electronic media, however, still show alcohol use as a normative and harmless behavior (Signorielli , 1993; Grube \& Wallack, 1994). Alcohol advertising is designed to appeal to children and adolescents. It sells images of success, sexuality, fun, and love, and it can be found in movies (no matter the rating), television, magazines, billboards, and radio (Garfield, et al., 2003; Strasburger \& Wilson, 2002; Sargent et al., 2006). Alcohol advertising is ubiquitous in sporting events and broadcast media and is also present on the Internet. Each year the alcohol industry spends more than $\$ 1$ billion on television, radio, print, and outdoor advertising (Federal Trade Commission, 2003). Alcohol advertisements are often more concentrated in media directed to youth than in media directed to adults. Accumulating evidence suggests that alcohol advertising may contribute to adolescent drinking (http://camy.org /research /files/ overexposed0902.pdf., 2002). The alcohol industry's voluntary advertising codes provide that alcohol advertising should not be overtly directed to underage consumers (Federal Trade commission, 2003). Other studies have made similar findings: the more T.V. that adolescents watch, the more positive they feel about smoking, the more likely they are to begin smoking, and the sooner they start smoking (Gutschoven \& Van den Bulck, 2005). Racial differences in the effects of peer and media influence on adolescents' alcohol cognitions and consumption were examined in a large-scale panel study. The results 
suggest media influence works in a similar manner to social influence and that Whites may be more susceptible to both types of influence (Frederick, 2010).

Now days, media is playing a vital role in formation of attitude and the shaping of the personality. In to-days globalization scenario media and communication is playing a major role saving the information globing (Chuang \& Chuang , 2008). But impact of media is very high on public sometimes it is negative and positive also. From the above review of literature suggest that recent increase in health risk behavior is due to changes in the social environment that multiply the action of previously unsuccessful procedures and very less attentions towards the communication and behavioral models and prevention studies should be directed toward critical steps in the developmental history of health risk behavior. More research on how the media influence drug use is needed in order to evaluate the impact of such drama. With media and risky behaviours, it is important to walk with caution, as the line between reality and glamorisation is easy to cross. More research is needed that investigates direct, indirect, and interactive effects of media portrayals on risky behaviour.

To know the role of media in relation to health risk behavior the present study was planned with the following objectives:

1. To assess the preference and programmes preferred by male and female.

2. To assess the duration of watching television and importance to health related programmes.

3. To assess their attitudes towards health related programmes.

4. To assess frequently reported health risk behaviour and its impact.

\section{METHODOLOGY}

\section{Sample:}

Table I : Socio-demographic details of the sample

\begin{tabular}{|l|l|l|l|}
\hline Sl. No. & Sub - Group & N & Percentage (\%) \\
\hline 1. & Gender & & \\
& Male & 25 & 50.0 \\
\hline 2. & Female & 25 & 50.0 \\
\hline 3 & Age & 14 & \\
& $18-35$ yrs. & 36 & 28.0 \\
& $36-55$ yrs. & & 72.0 \\
\hline 4 & Locality & 11 & \\
& Urban & 39 & 22.0 \\
& Rural & & 78.0 \\
\hline & Economic status & 07 & \\
& Poor & 41 & 14.0 \\
& Low middle & 01 & 82.0 \\
& middle & & 02.0 \\
\hline
\end{tabular}


The selection of the sample was done randomly in Siddavatam village and Kadapa town. Table. I show the socio-demographic details of the sample. The sample details shows that in the present study male and female are equally distributed (male $=25$; female $=25$ ). The age group of the sample indicate that 28 percent of them are below 35 and $72 \%$ of them are above the age of 35 years. The locality details show that 22 percent of them belong to urban and 78 percent of them belong to rural areas. In the sample majority of them 82 percent belong to low middle category, 14 percent of them were poor and only 2 percent belongs to middle class (Table. I).

\section{Tools and testing method:}

After obtaining prior information, the subjects were contacted individually at their home and explained the purpose of the study and seeking their co-operation. The structure schedule was given to the subjects with a request to fill them at their leisure time. The schedule which was prepared in Telugu, which is a regional language.

\section{RESULTS AND DISCUSSION}

Mass media can potentially influence behaviours. For example, research indicates that the more adolescents are exposed to movies with smoking the more likely they are to start smoking. Youngsters are routinely involved in multitasking, makes it important to distinguish between media use and media exposure particularly health risk behavior. A thorough understanding of the nature of the media impact on health and well-being is a vital component of the public health agenda. The results of the present study are presented and discussed as mentioned below: Firstly, the subjects responses related their interest towards media was collected. Further analysis was carried out to see their interests related to health related aspects. Finally, the subjects perceptions related to health risk behaviour and its impact on children and adolescents were analysed. Table. II shows preference of watching television by sample. From the above table it is clear that only 44 percent were preferring to watch along with family members and 56 percent preferred to watch lonely.

Table II: Preference of watching T.V. as reported by the subjects

\begin{tabular}{|l|l|l|l|}
\hline Sl. No. & Sub - Group & N & Percentage (\%) \\
\hline 2. & Preference of watching with Family & 22 & 44.0 \\
\hline 3. & Preference to watch lonely & 28 & 56.0 \\
\hline
\end{tabular}

Table. III shows programmes preferred by the sample. From the details, it is evident that 78 percent prefer to watch recreational channels, and 64 percent preferred musical channels and only 34 percent of them preferred sports. 32 percent of them were regularly watching news channels, only 10 percent preferred spiritual and only 4 percent were watching scientific channels. 
Table III: Preference of Programmes as reported by the subjects

\begin{tabular}{|l|l|l|l|}
\hline Sl. No. & Programmes preferred & N & $\mathbf{\%}$ \\
\hline 1. & Recreational & 19 & 38 \\
\hline 2. & Musical & 8 & 16 \\
\hline 3. & Sports & 6 & 12 \\
\hline 4. & News & 10 & 20 \\
\hline 5. & Spiritual & 5 & 10 \\
\hline 6. & Scientific & 2 & 4 \\
\hline
\end{tabular}

To realize the objective2, the data was collected on channels preferred by the sample. The data clearly shows that among the entertainment channels Gemini t.v. (44\%) is highly preferred channel followed by E t.v.,(24\%), Maa t.v. (20\%) and Zee t.v. (40\%) (vide Table .IV) .

Table IV: Preference of Channels as reported by the subjects

\begin{tabular}{|l|l|l|l|}
\hline Sl No. & Channel preferred & $\mathbf{N}$ & $\mathbf{\%}$ \\
\hline 1. & Gemini T.V. & 22 & 44 \\
\hline 2. & E T.V & 12 & 24 \\
\hline 3. & Maa T.V & 10 & 20 \\
\hline 4. & Zee T.V & 6 & 12 \\
\hline
\end{tabular}

Further analysis was carried out to get the duration of watching television as reported by the subjects(See Table. V). From the results it is evident that majority of the subjects i.e., nearly 52 percent of them were regularly watching t.v. 2 to 4 hrs. of duration. 32 percent reported 1 hour and only 14 percent of them were spending more 4 to 6 hours and only 2 percent spending more than 8 hrs. From the above we can say that majority of the subjects spending more than 3 hours on watching television.

Table V: Preference of Channels as reported by the subjects

\begin{tabular}{|l|l|l|l|}
\hline Sl No. & Duration of watching T.V. & $\mathbf{N}$ & $\mathbf{\%}$ \\
\hline 1. & $>1$ hour & - & - \\
\hline 2. & 2 to 4 hrs. & 26 & 52 \\
\hline 3. & 4 to 6 hrs. & 07 & 14 \\
\hline 4. & 6 to 8 hrs. & 16 & 32 \\
\hline 5. & $<8$ hrs. & 2 & 02 \\
\hline
\end{tabular}

The data was collected on health related programmes in television are (vide Table VI). From the above table it is clear that majority of the subjects (56\%) stated that media is low preference to health related advertisements. The same trend was in relation to importance given to health related programmes (vide Table VII). Also reported that they are influenced by health related programmes and benefitted by watching health related programmes their personal opinion 
clearly revealed that they are getting knowledge related health conditions of different in nature. But they stated that majority of them are not discussing with others and were not directly participated in the programmes. But they are following the suggestions given by the experts.

Table VI: Attitudes towards preference of health related programms as reported by the Subjects

\begin{tabular}{|l|l|l|l|l|l|l|l|}
\hline Sl No. & Preference & \multicolumn{2}{l|}{ Low } & \multicolumn{2}{l|}{ Average } & \multicolumn{2}{l|}{ High } \\
\cline { 4 - 9 } & & $\mathbf{N}$ & $\mathbf{\%}$ & $\mathbf{N}$ & $\mathbf{\%}$ & $\mathbf{N}$ & $\%$ \\
\hline 1. & $\begin{array}{l}\text { Preference to health related } \\
\text { advertisements }\end{array}$ & 18 & 36 & 20 & 40 & 12 & 24 \\
\hline 2. & $\begin{array}{l}\text { Importance to health related } \\
\text { programmes }\end{array}$ & 28 & 56 & 06 & 12 & 16 & 32 \\
\hline
\end{tabular}

Table. VII: Attitudes on health related programmes as reported by the subjects

\begin{tabular}{|c|c|c|c|c|c|}
\hline \multirow[t]{2}{*}{ SI No. } & \multirow[t]{2}{*}{ Preference } & \multicolumn{2}{|c|}{ Yes } & \multicolumn{2}{|c|}{ No } \\
\hline & & $\mathbf{N}$ & $\%$ & $\mathbf{N}$ & $\%$ \\
\hline 1. & $\begin{array}{l}\text { Are you following suggestions given in health related } \\
\text { programmes? }\end{array}$ & 13 & 26 & 37 & 74 \\
\hline 2. & Are you influenced by health related programmes? & 40 & 80 & 10 & 20 \\
\hline 3. & Are you going to discuss health related with others? & 13 & 26 & 37 & 74 \\
\hline 4. & $\begin{array}{l}\text { Are you interested to participate in health related } \\
\text { programmes? }\end{array}$ & 12 & 24 & 38 & 76 \\
\hline 5. & $\begin{array}{l}\text { Are you benefitted by watching health related } \\
\text { programmes? }\end{array}$ & 35 & 70 & 15 & 30 \\
\hline 6 & $\begin{array}{l}\text { Are you following tips given by health experts of health } \\
\text { related programmes? }\end{array}$ & 43 & 86 & 7 & 14 \\
\hline
\end{tabular}

Table VIII shows health risk behaviour frequently appeared in media. The respondents of the subjects clearly shows that in Indian media particularly in serials the health risk behaviours like smoking(75\%), drinking(75\%), violence (68\% ), and drug usage (86\%) is frequently appeared compared to sex initiation (24\%). 
Table VIII: Health risk behaviour frequently appeared in Media as reported by the subjects

\begin{tabular}{|l|l|l|l|l|l|}
\hline Sl. & Scenes related to Health risk & \multicolumn{2}{|l|}{ Frequently } & \multicolumn{2}{l|}{ Rarely } \\
\cline { 4 - 7 } No. & behavior & N & \% & N & $\%$ \\
\hline 1. & Smoking & 35 & 70 & 15 & 30 \\
\hline 2. & Drinking & 38 & 76 & 12 & 24 \\
\hline 3. & Gambling & 36 & 72 & 14 & 28 \\
\hline 4. & Drug Usage & 43 & 86 & 07 & 14 \\
\hline 5. & Sex initiation & 12 & 24 & 38 & 76 \\
\hline 6. & Violence & 34 & 68 & 16 & 32 \\
\hline
\end{tabular}

Further analysis was carried out the assess the perceptions related to impact of health risk behavious on children and adolescents (Table IX). The male subjects, those who are aged 3655yrs. and the rural reported average to high impact of health risk behaviour on children and adolescents compared to female, those who are below 35 yrs. and urban counterparts.

Table IX: Perceptions related to Impact of Health risk behaviour on children and adolescents

\begin{tabular}{|c|c|c|c|c|c|}
\hline \multirow[b]{2}{*}{$\begin{array}{l}\text { Sl. } \\
\text { No. }\end{array}$} & \multirow[b]{2}{*}{ Sub-Groups } & \multirow[t]{2}{*}{$\mathbf{N}$} & \multirow{2}{*}{\begin{tabular}{|l} 
Poor \\
F (\%)
\end{tabular}} & \multirow{2}{*}{\begin{tabular}{|l} 
Average \\
F (\%)
\end{tabular}} & \multirow{2}{*}{\begin{tabular}{|l|} 
High \\
F (\% )
\end{tabular}} \\
\hline & & & & & \\
\hline \multicolumn{6}{|c|}{ GENDER } \\
\hline \multirow[t]{2}{*}{1.} & Male & 25 & $4(16)$ & $7(28)$ & \begin{tabular}{|l|}
$14(56)$ \\
\end{tabular} \\
\hline & Female & 25 & $6(24)$ & $8(32)$ & 11(44) \\
\hline \multicolumn{6}{|c|}{ AGE } \\
\hline \multirow[t]{2}{*}{2.} & $18-35$ & 14 & \begin{tabular}{|l}
$5(35.71)$ \\
\end{tabular} & \begin{tabular}{|l|}
$5(35.71)$ \\
\end{tabular} & \begin{tabular}{|l}
$4(28.57)$ \\
\end{tabular} \\
\hline & 36-55 & 36 & $12(33.33)$ & $10(27.77)$ & $14(38.8)$ \\
\hline \multicolumn{6}{|c|}{ LOCALITY } \\
\hline \multirow[t]{2}{*}{3.} & Urban & 11 & $2(18.18)$ & $3(27.27)$ & 6(54.54) \\
\hline & Rural & 39 & 9(23.07) & 12(30.76) & 18(46.1) \\
\hline
\end{tabular}

From the above analyses of results, it is evident that watching television is a major source of entertainment particularly in countries like India where majority of the population still living in rural areas depended on agriculture. The above results clearly show that there is increase related awareness of health related programmes. And they felt health risk behaviour which is depicted in the major entertainment channels is affecting the children and adolescence.

\section{Important findings of the study:}

Health risk behaviors-physical inactivity, poor eating habits, smoking, alcohol use, sexual behaviors, and violence- that contribute to the leading causes of death and disability. Adolescent health behaviors do not occur in isolation. They grow out of complex interactions at the 


\section{Health Risk Behaviour as Depicted in the Media}

individual, peer, family, school, community, and societal levels. Research suggests that repeated exposure to health risk behaviour prone the behaviour which directly makes the individual addicted to different malcoping habits. The subjects preferred recreational and musical channels compared to news and sports.

- Among the entertainment channels Gemini, Maa and Zee TV. is highly preferred compared to others.

- Nearly $70 \%$ of subjects are spending 2 to 6 hrs. In watching television.

- The subjects reported that less preference is given to health related advertisements.

- Nearly $75 \%$ of the subjects reported that they are watching and following health related programmes in Media.

- Nearly 25\% reported that they are not discussing health related issues with others and not participating in health related programmes.

- $\quad 75 \%$ of the subjects reported that smoking, drinking and durg usage scenes are frequently shown in the serials and movies broadcasted by the channels.

- $80 \%$ of the subjects reported that health risk behaviour problems repeated in the media has its impact on children and adolescence, when they are attached to main roles played in serials or in movies.

\section{Conclusions and Implications:}

Media plays a very significant and influential role in our day today life. Everyday programs include advertisement and entertainment programmes like serials etc., but in recent times, everyday at least five risky behaviours are witnessed by the public. Due to lack of vigilance from the parents the youth are habituated to excessive caloric intake, physical inactivity, smoking, underage drinking, early sexual initiation, and violent behavior etc., The links between media consumption and smoking and alcohol use also are strong and there is good evidence that they are causal. Currently there is need of high-quality research to make it possible to say whether the links are causal. To better understand the effect of the media on youth risk behavior, researchers will have to develop comprehensive explanatory models that include socioeconomic and cultural variables.

Despite few limitations, findings have valuable implications. First, it is important for parents and health care professionals who care for adolescents to have a basic understanding of health associated risks and benefits for teens; Second, Pediatricians often counsel parents that part of being a good parent is understanding how much time their children spend their time in watching television; Third, data should be generated to identify teens who are considering or engaging in health risk behaviors; Because current methods fail to identify many adolescents who may be strongly considering or are actually engaging in health risk behaviors, innovative approaches are clearly needed; Fourth, adolescents need guidance on safe Internet use. Given the dangers associated with displaying personal risk behavior information online, health care professionals should be able to discuss with risky group. Further study is needed to assess the 
validity of repeated exposure to health risk behaviour and how to promote healthy behaviors using with media.

\section{REFERENCES:}

Abelman, R. (2001). Parents' Use of Content-Based TV Advisories. Parenting: Science \& Practice, 1, 37-265.

Chuang Ying-Chih, and Chuang Kun-Yang (2008) Gender differences in relationships between social capital and individual smoking and drinking behavior in Taiwan. Social Science \&amp; Medicine, 67(8), 1321-1330.

Considine, D. M., \& Haley, G. E. (1992). Visual messages: Integrating imagery into instruction. Englewood, CO: Teacher Ideas Press.

Corder-Bolz, C.R. (1980 ). Mediation: The role of significant others. Journal of Communication, 30(3), 106-118.

Dorr, A., \& Rabin, B. E. (1995). Parents, children, and television. In M. Bornstein (Ed.), Handbook of parenting, Vol. 4 (pp. 323-351). Mahwah, NJ: Lawrence Erlbaum.

Federal Trade Commission,2003. Cigarette Report for 2003.Available from www.ftc.gov/reports/cigarette05/050809cigrpt.pdf.

Frederick X. Gibbons, Elizabeth A. Pomery, Meg Gerrard, James D. Sargent, Chih-Yuan Weng, Thomas A. Wills, John Kingsbury, Sonya Dal Cin, Keilah A. Worth, Mike Stoolmiller, Susanne E. Tanski, Hsiu-Chen Yeh. (2010). Media as Social Influence: Racial Differences in the Effects of Peers and Media on Adolescent Alcohol Cognitions, and Consumption. Psychology of Addictive Behaviors, 24(4),649-659.

Garfield, C. F., Chung, P. J. and Rathouz, P. J. (2003). Alcohol Advertising in Magazines and Adolescent Readership. JAMA: Journal of the American Medical Association, 289(18), 2424-29.

Gidwani, P. P. et al., (2002). Television Viewing and Initiation of Smoking among Youth. Pediatrics, 110(3), 505-08.

Grube, J. W. and L. Wallack. (1994). Television Beer Advertising and Drinking: Knowledge, Beliefs,and Intentions among Schoolchildren. American Journal of Public Health, 84(2), 254-59.

Gutschoven, K. and J. Van den Bulck (2005). Television Viewing and Age at Smoking Initiation: Does a Relationship Exist between Higher Levels of Television Viewing and Earlier Onset of Smoking?. Nicotine and Tobacco Research , 7(3), 381-85.

Heidi J. Keeler, Margaret M. Kaiser. (2010). An Integrative Model of Adolescent Health Risk Behavior. Journal of Pediatric Nursing, 25(2), 126-137.

John Cawley, Christopher J. Ruhm. (2011). The Economics of Risky Health Behaviors, In: Mark V. Pauly, Thomas G. Mcguire and Pedro P. Barros, Editor(s), Handbook of Health Economics, Elsevier. 2, 95-199.

Kelly Broadwater, Lisa Curtin, Denise M. Martz, Mark C. Zrull. (2006)., College student drinking: Perception of the norm and behavioral intentions. Addictive Behaviors, 31(4), 632-640. 


\section{Health Risk Behaviour as Depicted in the Media}

Kim, Young-Ho. (2001). Korean adolescents’ health risk behaviors and their relationships with the selected psychological constructs. Journal of Adolescent Health, 29(4), 298-306.

Rachel E. Myers(2010). Promoting healthy behaviors: How do we get the message across?. International Journal of Nursing Studies,47(4), 500-512.

Sargent, J. D. et al., (2006). Alcohol Use in Motion Pictures and Its Relation with Early-Onset Teen Drinking. Journal of Studies on Alcohol , 67(1) 54-65.

Signorielli, N. (1993). Mass Media Images and Impact on Health: A Sourcebook. Westport, Conn.: Greenwood Press.

Signorielli, N. (1993). Mass media images and impact on health: A sourcebook. Westport, Connecticut: Greenwood Press.

Strasburger, V. C. and Wilson, B. J. (2002). Children, Adolescents, and the Media . Thousand Oaks, Calif.: Sage.

Wachter, C. and Kelly,J. (1998). Exploring VCR Use as a Leisure Activity. Leisure Sciences , 20, 213-27.

Yates, B.L., (1999. Media literacy. A health education perspective. Journal of Health Education, 30(3), 183-18. 